\title{
IDENTIFICAÇÃO DAS RELAÇÕES ESPACIAIS DAS ÁREAS POTENCIALMENTE TURFOSAS DA ESCARPA DA ESPERANÇA - GUARAPUAVA-PR
}

Fabíula Eurich Machado ${ }^{1}$ Maurício Camargo Filho² Marcos Aurélio Pelegrina ${ }^{3}$

Resumo: As turfeiras podem ser definidas como um sistema que retém e conserva materiais de origem vegetal. Para estudos paleoambientais as turfeiras servem como bancos de dados sobre os climas que já vigoraram no passado, visto que são formadas pelo acumulo de materiais vegetais, em locais saturados de água, baixo $\mathrm{pH}$ e temperaturas amenas, impossibilitando e/ou reduzindo a ação de microorganismos decompositores. No entanto na região de Guarapuava estudos voltados à aquisição de informações sobre esses ambientes são escassos. 0 objetivo desse trabalho é avaliar a distribuição e padrões das turfeiras presentes na folha topográfica Guarapuava e Itapará (MI 2838-3 e MI 2838-4, respectivamente) e relacioná-las com as feições geomorfológicas, a fim de encontrar o motivo da alta concentração desse ambiente na região. A combinação entre os elementos morfoestruturais e morfoesculturais atua com forte influência nas turfeiras desde a sua formação ao seu processo atual. No caso específico da área de estudo a questão estrutural é determinante para o controle dos ambientes turfosos.

Palavras-chave: Quaternário. Turfeiras. Morfoestrutura. Sensoriamento remoto. Classificação supervisionada.

\section{IDENTIFICATION OF THE SPATIAL RELATIONSHIPS OF THE POTENTIALLY PEATY AREAS OF ESPERANÇA ESCARPMENT - GUARAPUAVA-PR}

Abstract: Peatlands can be defined as a system that retains and preserves plant materials. For paleoenvironmental studies peatlands serve as databases of the climate and its states in the past, because they are formed by the accumulation of plant material in water-saturated environments, with low $\mathrm{pH}$ and mild temperatures, preventing or at least reducing decomposition by microorganisms. However, in Guarapuava region, studies focused on acquiring information about these environments are scarce. The aim of this study is to evaluate the distribution and patterns of the peatlands present in the topographic sheets of Guarapuava and Itapará ( $\mathrm{Ml}$ 2838-3 and 2838-4 MI, respectively) and relate them to the geomorphological features in order to find the reason for the high concentration of these environments in the region. The combination of morphostructural and morphoscultural elements acts as a strong influence on a peatland from its formation on towards its current process. In this study, the structural issue is crucial to the control of peaty environments.

Keywords: Quaternary. Peatland. Morphostructure. Remote sensing. Supervised lassification.

\footnotetext{
${ }^{1}$ Universidade Estadual do Centro-Oeste, Departamento de Geografia, Guarapuava, Brasil, fabiula.machado@hotmail.com, https://orcid.org/0000-0002-2605-2605

2 Universidade Estadual do Centro-Oeste, Departamento de Geografia, Guarapuava, Brasil, mcamargo12@hotmail.com, https://orcid.org/0000-0002-6306-9043

${ }^{3}$ Universidade Estadual do Centro-Oeste, Departamento de Geografia, Guarapuava, Brasil, marcospelegrina@gmail.com, https://orcid.org/0000-0002-7424-7722
} 


\section{IDENTIFICACIÓN DE LAS RELACIONES E SPACIALES DE LAS ÁREAS POTENCIALMENTE TURFOSAS DE LA ESCARPA DE LA ESPERANÇA - GUARAPUAVA-PR}

Resumen: Las turberas pueden definirse como un sistema que retiene y conserva materiales de origen vegetal. Para los estudios paleoambientales, las turberas sirven como bases de datos del clima y sus estados en el pasado, porque están formadas por la acumulación de material vegetal en entornos saturados de agua, con bajo $\mathrm{pH}$ y temperaturas bajas, evitando 0 al menos reduciendo la descomposición por microorganismos. Sin embargo, en la región de Guarapuava, los estudios centrados en la adquisición de información sobre estos entornos son escasos. El objetivo de este estudio es evaluar la distribución y los patrones de las turberas presentes en las hojas topográficas de Guarapuava e Itapará (MI 2838-3 y 2838-4 MI, respectivamente) y relacionarlas con las características geomorfológicas para encontrar la razón de la alta concentración de estos ambientes en la región. La combinación de elementos morfoestructurales y morfoesculturales actúa como una fuerte influencia sobre una turbera desde su formación hacia su proceso actual. En este estudio, la cuestión estructural es crucial para el control de los ambientes turberos.

Palabras clave: Cuaternario. Turberas. Morfoestructura. Sensoriamiento remoto. Clasificación supervisada.

\section{Introdução}

A paisagem é o resultado de um lento processo natural de reordenação e equilíbrio de micro e macro ecossistemas. As alterações, transformações e variações sucedidas no período Quaternário foram relativamente mais rápidas quando comparados a outros períodos geológicos, o que potencializa a importância desse período para investigações e inferências de processos naturais pretéritos, assim como estudos das formas de vida e de condições específicas em alguns locais da Terra. Compreender o período Quaternário significa entender como se deu parte dos processos de evolução e transformação dos quadros ecológicos e formas de vida conhecidas hoje.

A relevância que o período Quaternário adquiriu nos segmentos científicos justifica-se em razão de que dele é possível se obter informações sobre como era a dinâmica e o comportamento do planeta no passado geológico recente. Considerando-se que a sensibilidade ambiental de um ecossistema pode acusar quais foram as mudanças ocorridas nas condições atmosféricas locais e globais (WOODWARD, 2009), as áreas de turfeiras são um ponto excepcionalmente vantajoso para esse tipo de investigação.

Formados no Quaternário, os ambientes turfosos são sistemas que tem em sua formação restos vegetais em decomposição e acúmulo de água (DJUWANSAH, 
2000). Segundo Pereira et al. (2005), as turfeiras são resultado de sistemas geomorfológicos, processos geológicos globais e condições ideais de acumulação de restos orgânicos.

Por apresentar dinâmica singular, as turfeiras denotam um caráter único e importante dentro de uma bacia hidrográfica, controlando a dinâmica e a qualidade da água ao armazená-la em períodos de chuva e liberá-la em períodos secos. Outra característica relevante é seu poder de acumular carbono ao longo de milhares de anos (SHIMADA et al., 2000; PARRY; CHARMAN, 2013). Essa capacidade de reter e preservar materiais ao longo do tempo torna esse ambiente privilegiado para os estudos geomorfológicos, pois serve como proxy ${ }^{4}$ de arquivos do passado.

Assim sendo, os ambientes turfosos são verdadeiras coleções de arquivos com referências bastante precisas sobre a evolução ambiental. As turfas estão inteiramente sujeitas à umidade do ambiente, portanto, são sensíveis e dependentes das condições atmosféricas que as constituem.

Dentre as pesquisas com essa perspectiva, desenvolvidos na região da área de estudo, destaca-se a realizado por Silva (2013), que trabalhou especificamente com uma turfeira. $\mathrm{O}$ autor citado, conseguiu estabelecer uma cronologia de eventos que a turfa foi submetida ao longo do tempo, permitindo compreender, ao menos em parte, a evolução ambiental do município de Guarapuava nos últimos $14 \mathrm{Ka}$. Outro pesquisador a desenvolver trabalhos na região foi Lima (2009), que descreveu o controle geológico e geomorfológico na rede de drenagem sobre a formação de rochas vulcânicas básicas, litologia essa também encontrada na área de estudo.

Embora seja amplamente reconhecida a importância desse ambiente para coleta de informações de dinâmicas ocorridas no passado, há poucos trabalhos sobre a região que expliquem o motivo de sua concentração e informações básicas sobre sua proporção e delineamentos. Neste sentido, o presente estudo corrobora para que as áreas turfosas na região de Guarapuava sejam efetivamente caracterizadas e identificadas, considerando que se faz necessário monitorá-las e protegê-las, de modo a auxiliar os órgãos e institutos de proteção desses ambientes. Para realizar tarefa desta grandeza, o meio seguro e eficaz encontrado foi o uso do sensoriamento remoto como ferramenta para sua identificação.

As vantagens na utilização do sensoriamento remoto se devem a três aspectos: a resolução espacial, que permite a obtenção de informações em

\footnotetext{
${ }^{4}$ Dados proxy são dados paleoclimáticos reunidos a partir de gravadores naturais de variabilidade climática (NOAA, 2008).
} 
diferentes escalas, a resolução espectral, que gera dados sobre um alvo na superfície terrestre e a resolução temporal, que reúne dados de várias épocas e distintos anos. Além disso, o sensoriamento remoto permite estudos em grandes extensões. Conforme Novo (1995), a geomorfologia é o campo da Geografia que mais se beneficia com a tecnologia do sensoriamento remoto, pois esta permite identificar e visualizar os mais variados tipos de feições e fenômenos geomorfológicos.

Em hipótese, as turfeiras do reverso da escarpa da Esperança, abrangidas pelas cartas topográficas "Guarapuava" e "Itapará" (Ml 2838-3 e Ml 2838-4, respectivamente), apresentam padrão de distribuição espacial vinculado aos controles morfoestrutural e morfoescultural da área estudada, pois a natureza litológica e geomorfológica pode atuar na formação e manutenção de ambientes específicos (BIGARELLA, 1975; BÜDEL, 1948; PENCK, 1953; ROSS, 1991). A hipótese inicial sugere que as turfeiras estão predominantemente conectadas à rede de drenagem. Considerando que as turfeiras são áreas de banhado, pressupõe-se que a textura litológica pode ser um condicionante, que permite o acumulo de água nos níveis amigdaloides e vesiculares dos derrames que compõe a litologia do sítio.

Objetivo deste artigo é avaliar a distribuição e padrões espaciais das áreas turfosas conectadas e não conectadas à rede de drenagem, que predominam no reverso da Escarpa da Esperança, localizada no município de Guarapuava-PR, na porção das folhas topográficas "Guarapuava" e "Itapará" (MI 2838-3/ Folha SG.22-VD-III-3/ Ml 2838-4/ Folha SG 22-V-D-III-4, respectivamente) e relacioná-las com as feições geomorfológicas e litológicas.

\section{Caracterização da área de trabalho}

\section{Localização Geográfica}

As turfeiras analisadas estão localizadas nas folhas topográficas "Guarapuava" (MI 2838-3) e "Itapará" (MI 2838-4), do estado do Paraná. A área corresponde a aproximadamente 70.560 hectares, delimitados pelos paralelos $25^{\circ}$ $15^{\prime}$ e $25^{\circ} 30^{\prime}$ de latitude sul e os meridianos $51^{\circ} 00^{\prime}$ e $51^{\circ} 15^{\prime}$ de longitude Oeste de Greenwich. A área de estudo (figura 1) contempla parte do Segundo e do Terceiro Planaltos paranaenses, também chamados de Planaltos de Ponta Grossa e Guarapuava, respectivamente. 
Figura 1 - Localização da área de estudo.

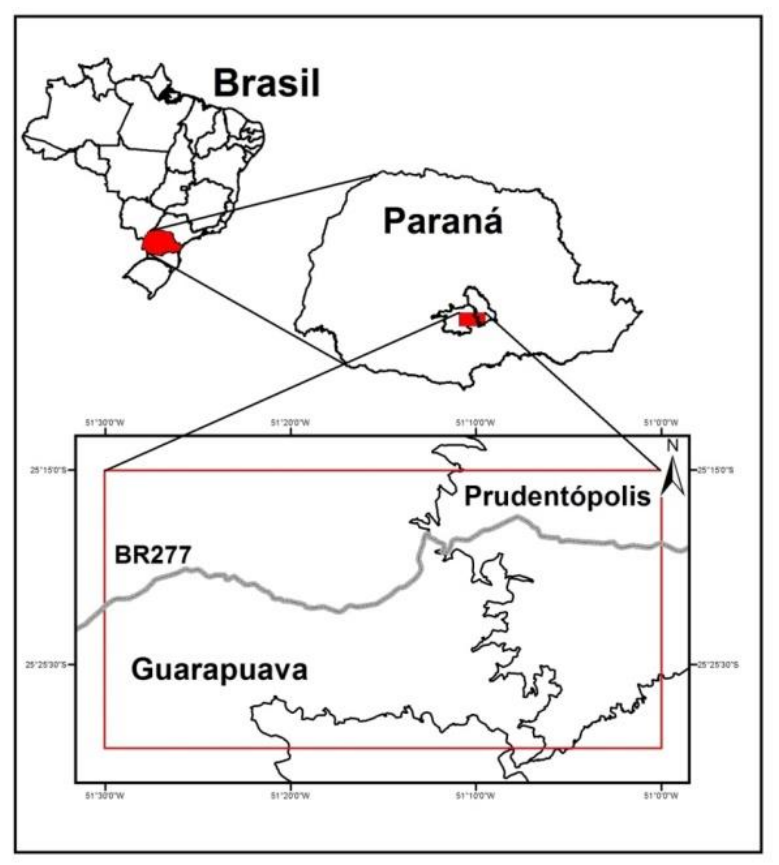

Fonte: Base cartográfica do IBGE. Elaborado pelos autores.

\section{Aspectos litológicos}

As rochas formadoras do território paranaense, as especificas do terceiro planalto paranaense, são predominantemente metamórficas e magmáticas, recoberta por rochas vulcânicas e sedimentares Paleozóicas e Mezozóicas, que constituem a Bacia do Paraná. De acordo com MINEROPAR (2006), as rochas do Paraná têm idades de 2,8 bilhões de anos até o presente, sendo formadas por compartimentos distintos que abrangem um extenso intervalo do tempo geológico. A área de estudo está assentada sobre os depósitos da Bacia do Paraná que, de acordo com Rostirolla et al (2000), são depósitos compostos basicamente por rochas siliciclásticas, constituindo unidades que foram formadas no período Paleozoico e Mesozoico.

O quadro estrutural da Bacia do Paraná apresenta três direções estruturais principais, a saber: lineamentos EW, lineamentos NE-SW e lineamentos de direção NW-SE. Dentro da ocorrência Serra Geral, as estruturas que se destacam pela importância ao longo da história geológica são o Arco de Ponta Grossa e os lineamentos de Rio Piquiri, Rio Alonzo, São Jerônimo-Curiúva e Jacutinga, com direções NE e NW predominantes (MINEROPAR, 2013). 


\section{Aspectos geomorfológicos}

Com relação ao relevo da área de estudo, Camargo Filho (1997) destaca que é formado por morros, encontrados em porções pouco elevadas, e vastas encostas, abrangendo grandes extensões, limitadas pelas partes mais elevadas no sentido leste do estado em direção das bordas da escarpa da Esperança. Bigarella et al (1994) afirmam que a sua natureza litológica e as características geomorfológicas dependentes das estruturas de derrames vulcânicos de fissura continental, nas quais as camadas de rochas basálticas deram lugar a plataformas estruturais, apresentam vantagens, já que suas formas estruturais regulam a progressão de atividades de erosão.

Conforme o Instituto de Terras Cartografia e Geociências - ITCG (2008) e MINEROPAR (2006), o relevo regional abrangido pela área de estudo é formado pelas subunidades morfoesculturais dos Planaltos de Prudentópolis; Residuais; Pitanga/Ivaiporã; Palmas/ Guarapuava; e Foz do Areia. Com vertentes convexocôncavas e vales em "V". A classe de declividade predominante está entre 6-30\%.

\section{Clima}

Considerando a classificação climática de Köppen, a região está sob influência do clima tipo Cfb-Clima Temperado, com médias de $18^{\circ} \mathrm{C}$ no mês mais frio e com $22^{\circ} \mathrm{C}$ no mês mais quente, representando verões frescos e sem estação seca definida (AYOADE, 1998; CAVIGLIONE et al, 2000). Thomaz e Vestena (2003) definem o clima da região como subtropical mesotérmico, úmido, sem estação seca, com verões frescos e inverno moderado.

Em relação aos aspectos de regime pluviométrico, segundo Thomaz e Vestena (2003) a pluviosidade da região apresenta-se bem distribuída ao longo das estações com médias mensais acima de $100 \mathrm{~mm}$ e anuais em torno de $1961 \mathrm{~mm}$, havendo variações entre as estações climáticas, contendo os meses de verão maior pluviosidade e inverno com redução.

\section{Solos}

A litologia local e seus processos dinâmicos condicionaram de maneira significativa a região para os solos existentes. A região apresenta solos ARGISSOLOS, CAMBISSOLOS, GLEISSOLOS, LATOSSOLOS, NEOSSOLOS e NITOSSOLOS (EMBRAPA, 1999; MÜLLER; POTT, 2004; ITCG, 2008). CAMBISSOLOS e NEOSSOLOS encontram-se em porção menores e estão fortemente relacionados com ondulações do relevo (EMBRAPA, 1999; GUERRA; CUNHA, 2003). 


\section{Vegetação}

Ab'Saber (2003) caracterizou genericamente o conjunto vegetacional da área como composto por campos e matas de Araucária (Floresta Ombrófila Mista) sob controle de planaltos subtropicais com Araucárias. Maack (1968) afirma que a região florística da área em questão é composta pela combinação entre campos limpos, capões e matas de galeria com floresta de Araucárias.

Especificamente no ambiente de turfeiras da região, a vegetação constituinte apresenta basicamente três grupos de plantas: Angiospermas, Pteridófitas e Briófitas. Incluído nesse último grupo está o Sphagnum, uma espécie comum em turfeiras de zonas climáticas temperadas, sendo representativo para análises de quadros ambientais, haja vista que esta espécie está atrelada a ambientes ácidos e frios, típicos do período Quaternário (SILVA, 2013).

\section{Materiais e Métodos}

Utilizou-se neste estudo como ferramenta o sistema de geoprocessamento aplicado na análise espacial, de modo à compreender e a manipular imagens através de ambientes de informações geográficas. Para Moura (2007) o processo "compreende a aquisição, tratamento e análise de dados espaciais". Dados multidisciplinares como espaciais e alfanuméricos que constituem o SIG, permitem que o conjunto paisagista da área de estudo seja caracterizado. A estrutura metodológica para o estudo pode ser observada na figura 2.

Figura 2- Estrutura metodológica do estudo.

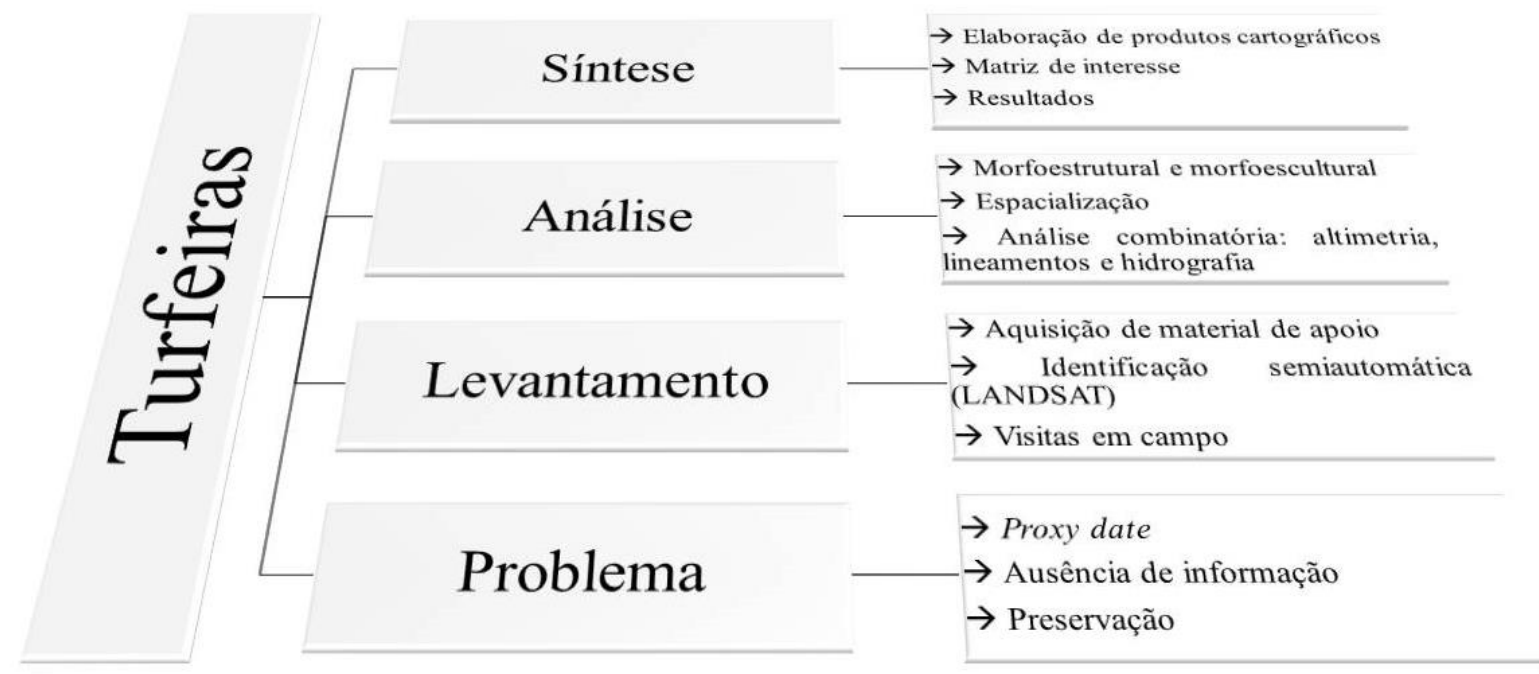

Elaborado por: EURICH MACHADO, F., 2016. 


\section{Materiais}

- Carta Topográfica do Instituto de Terras Cartografia e Geociências - ITCG, em escala 1: 50.000 (Guarapuava - MI- 2838-3/ Folha SG.22-V-D-III-3/ Itapará - MI2838-4/ Folha SG 22-V-D-III-4), ano de 1980.

- Imagens digitais do satélite LANDSAT 8, sensor OLI (Operation Land Imager), órbita 222, ponto 078, com data de 18 de janeiro de 2016, resolução espacial de 30 metros, adquiridas a partir do website do Instituto Nacional de Pesquisas Espaciais INPE, composição infravermelho 543/RGB.

- Modelo Digital de Elevação - MDE do projeto TOPODATA do Banco de Dados Geométricos do Brasil, com resolução espacial de 30 metros, disponibilizado pelo INPE (Folha 25S525).

- Carta Litoestratigráfica da MINEROPAR - Minerais do Paraná S/A, em escala 1: 250.000 (Folha de Guarapuava - SG-22-V-D) ano de 2005 e 2013.

- Dados e informações geoespaciais temáticos do ITCG anos de 2007 e 2008.

- Software QGIS 2.8 e ArcGis 10.3 ESRI ®.

- Máquina fotográfica NIKON D3200.

\section{Métodos}

O trabalho foi realizado seguindo basicamente três etapas: levantamento, análise e síntese. O recorte da área estudada foi realizado com base nos limites das cartas topográficas "Guarapuava" (MI- 2838-3) e "Itapará" (Ml-2838-4), compreendendo a parte nordeste do município de Guarapuava e a parte oeste do município de Prudentópolis, no estado do Paraná, definida de acordo com critérios de relevância local para estudos voltados à compreensão da evolução geomorfológica da superfície regional.

Estudos recentes realizados na área (SILVA, 2013; GUERREIRO JUNIOR et al, 2015), demostram que a região apresenta elevada concentração de turfeiras, embora não haja menção na literatura de informações que expliquem o motivo deste comportamento.

Para todas as etapas de desenvolvimento da pesquisa foram utilizados espaços da Universidade Estadual do Centro-Oeste - UNICENTRO, incluindo acesso ao acervo da biblioteca e uso dos laboratórios de Geotecnologias e Geomorfologia do departamento de Geografia. 
Para a detecção remota das turfeiras, bem como para o processamento digital da imagem LANDSAT 8, seguiu-se a metodologia proposta por Menezes (2015), Araújo (2015) e Congedo (2016). A classificação supervisionada das imagens orbitais foi realizada através do software QGIS, com utilização do SCP Plugin (SemiAutomatic Classification Plugin) e a identificação das turfas seguiu técnicas de fotointerpretação visual conforme os critérios dispostos por Marchetti e Garcia (1986); Novo (1995) e Florenzano (2007).

Para concretização da primeira etapa foram solicitadas pela internet ao INPE as imagens do satélite LANDSAT 8. Antes do processo de classificação, realizou-se o ajuste para a refletância de superfície e a correção da radiação atmosférica. Esta correção foi feita utilizando um arquivo MTL (arquivos de metadados das bandas) disponibilizado em conjunto com as imagens. A etapa é essencial, pois, segundo Menezes (2015), minimiza a influência dos fatores que compõe a atmosfera terrestre, uma vez que estes podem interferir nos valores de radiância e refletância captados pelos sensores orbitais.

$\mathrm{Na}$ sequência, realizou-se a composição infravermelha, com utilização das bandas 5, 4 e 3 para R-red, G- green, B-blue, respectivamente. A combinação das bandas seguiu descrição técnica apresentada pela USGS para realce em alvos com presença de água e diferenciação de vegetação (USGS, 2016).

Em seguida foram definidas as classes de interesse, identificados como ROI e realizado o treinamento. Os ROIs utilizados foram: turfeiras, floresta, águas, área urbana e cultura agrícola. Após o estabelecimento dos ROls na imagem foi possível obter as assinaturas espectrais para cada área de amostra selecionada. Para tal classificação foi adotado o método "Maximum Likelihood" (MaxVer). A última fase para a classificação semiautomática foi a geração da matriz de confusão para estimativa da acurácia. A sequência metodológica do processo pode ser observada na figura 3. 
Figura 3 - Sequência da classificação Semiautomática SCP-

Plugin.

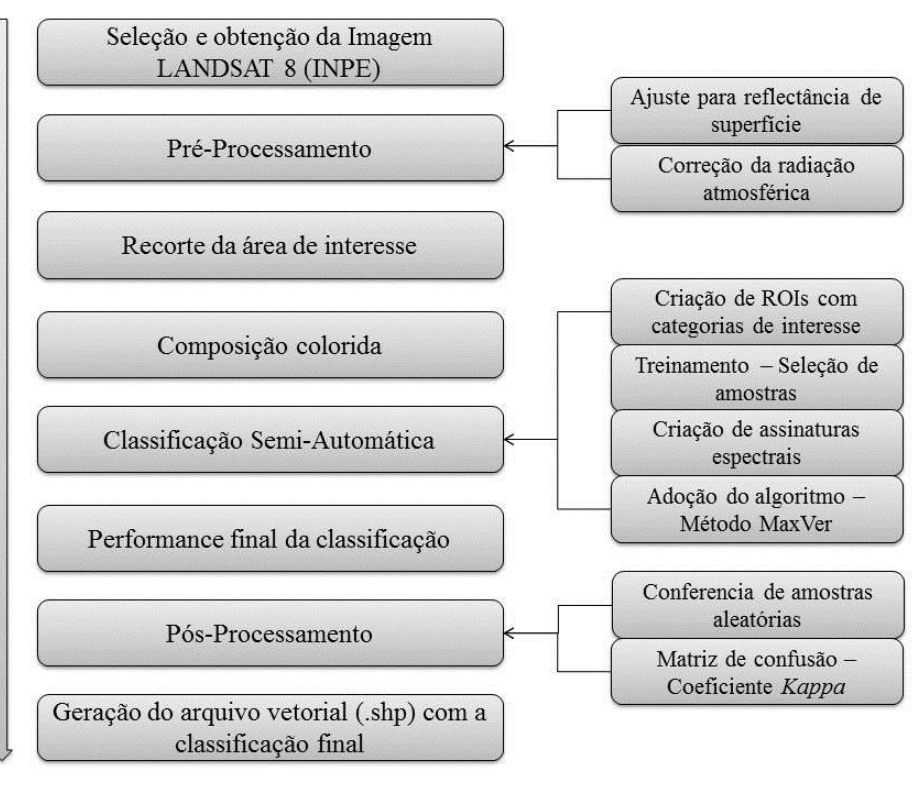

Organização: EURICH MACHADO, F., 2016.

Vale ressaltar que o plug-in permite, ao final do processo da classificação, gerar dois tipos de arquivos, um em formato raster5 e outro em formato vetor6, com as áreas semelhantes. Para o presente estudo utilizou-se apenas um ROI de interesse, isto é, o vetor pertencente ao ROI "turfeiras". Os outros ROls não participaram da analise final, uma vez que o objetivo desse processo era extrair somente a informação geoespacial das turfeiras.

\section{Extração automática da rede de drenagem e TIN - Triangular Irregular Network em ambiente ArcGIS}

A extração da rede de drenagem da área de estudo foi gerada a partir do MDE TOPODATA em ambiente ArcGis. O MDE foi baixado do sítio eletrônico do INPE, especificamente do Banco de Dados Geomorfométricos do Brasil. Os procedimentos foram realizados através da ferramenta Hidrology na extensão Spatial Analyst Tools, processo metodológico proposto por Andrades Filho et al (2009), Oliveira et al (2012) e Santos (2013).

Inicialmente foram preenchidos os vazios e possíveis imperfeições no raster, utilizando a ferramenta Fill sinks, que confere a consistência da drenagem, eliminando possíveis áreas de sumidouro. A seguir, foi feito o cálculo da direção de

\footnotetext{
${ }^{5}$ Arranjo matricial em que o valor ou código de uma célula representa todas as feições dentro de uma grade (CAMERA, 2005).

${ }^{6}$ São elementos de dados que permitem descrever posição e direção, podendo ser apresentados na forma de pontos, linhas ou polígonos (CAMERA, 2005).
} 
fluxo (Flow Direction), definindo a trajetória do fluxo em áreas subjacentes em pontos de menor altitude. Depois, foi obtida a matriz de acumulação de fluxo (Flow Accumulation), sendo então gerada a rede de drenagem, em que se considerou a acumulação de fluxo a partir da técnica limiar de fluxo acumulado. O limiar estabelecido foi de 500 pixels. A ferramenta con foi utilizada para a definição dos limiares. Para definição vetorial dos canais foi utilizado a ferramenta stream to feature.

Nas análises de elevação do terreno, foi representada a topografia da superfície a partir dos dados MDE com mapa TIN com as diferentes declividades. A superfície é representada de modo contínuo por uma organização de triângulos planos, permitindo o discernimento do comportamento do relevo pelo comportamento da dimensão relativa e pela densidade de triângulos (FIRKOWSKI, 2002). Os procedimentos foram elaborados conforme o disposto por Santos (2013) e Souza (2015), seguindo essa sequência de ferramentas: i) 3D Analyst Tools; ii) Conversion; iii) From Raster; e iv) Raster to TIN.

Para que fosse possível a criação de uma representação gráfica que caracterizasse a frequência de distribuição das turfeiras na área de estudo foi necessária a transformação dos arquivos de polígonos para pontos, com o propósito de fazer com que os pontos que representam cada turfeira adquirissem informação codificada dos valores altimétricos. Para o procedimento, os valores altimétricos foram extraídos a partir dos dados MDE, seguindo o caminho: i) 3D Analyst Tools; ii) Functional Surface; e iii) Surface Spot.

A plotagem das informações adquiridas completas de sites oficiais, juntamente com as informações geradas a partir da sequência de processos técnicos, foi realizada em ambiente $\operatorname{ArcGis}{ }^{\circledR}$. $\bigcirc$ ambiente possibilitou a sobreposição de camadas raster e vetorial para as análises correlatórias, a partir das correlações entre interpretação visual e conhecimento prévio da área de estudo.

O critério para escolha dos pontos de coleta de dados em campo, foi o agrupamento espacial das turfeiras em locais específicos percebidos nos produtos cartográficos. As análises correlatórias das informações retiradas em campo com as informações cartográficas apoiaram-se em trabalhos de gabinete com suporte da bibliografia especializada.

\section{Resultados e Discussões}

\section{Distribuição espacial das turfeiras}


As turfeiras da região ocupam uma área total de 2.856 hectares, correspondendo à $4 \%$ da área total analisada, sendo perceptível seu agrupamento em maior densidade na porção central do recorte de estudo (figura 4). Os tamanhos em área variaram do menor, 0,8100 hectares, ao maior, 79,7400 hectares. Sendo que as observações com área menor que 0, 8100 hectares foram descartadas da análise, devido à resolução da imagem e também para eliminar áreas não representativas e dados discrepantes (outliers) que pudessem interferir nas análises estatísticas disfarçando os dados reais.

Para a classificação supervisionada semiautomática da imagem LANDSAT 8, foi necessária a criação de várias classes e somente depois a classe alvo foi extraída. Para verificar a confiabilidade da classificação supervisionada, foi utilizado o índice kappa, que mede a confusão entre pixels no momento da aquisição das assinaturas espectrais e posterior classificação. Nesse caso não foi utilizado o índice kappa geral, mas somente o índice que se referia a classe turfeiras. $O$ valor do índice kappa para essa classe foi de 0,95, indicando o resultado para essa classe como excelente, de acordo com Moreira (2001).

Figura 04 - Distribuição espacial das turfeiras.

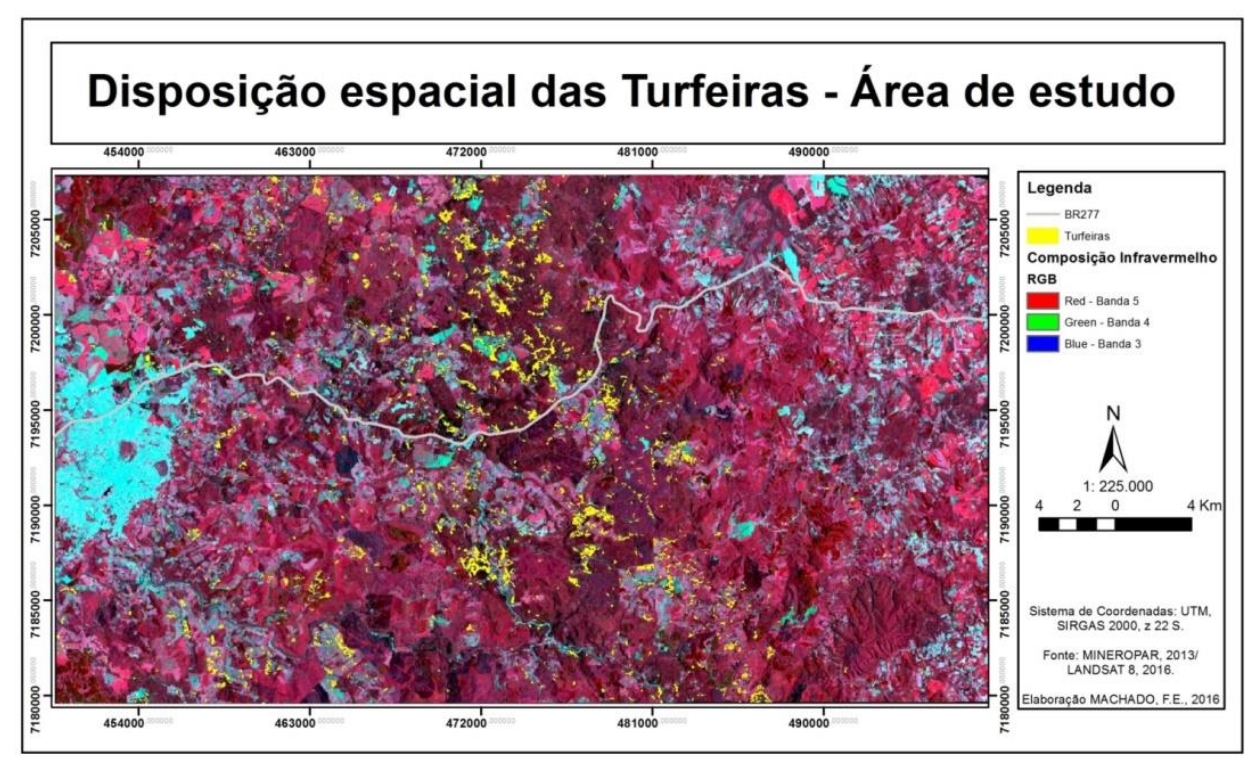

Fonte: Dados da pesquisa.

O total dos polígonos referente às áreas turfosas extraídos da classificação semiautomática foram de 1.225. No quadro 1 é possível observar a divisão, com relação a área das turfeiras, nota-se que as turfeiras ocorreram em maior grupo no valor limite de 0,8100 hectares, abrangendo $32 \%$ da área total classificada. 


\section{Quadro 1 - Classificação das turfeiras com relação às áreas divididas em} quartis. Org.: EURICH MACHADO, F., 2016.

\begin{tabular}{|c|c|c|c|}
\hline Área & Observações & $\%$ & $\begin{array}{c}\text { Quartil Valor Limite } \\
\text { (ha) }\end{array}$ \\
\hline 1. Quartil & 394 & $32 \%$ & 0,8100 \\
\hline 2. Quartil & 237 & $19 \%$ & 1,1700 \\
\hline 3. Quartil & 303 & $25 \%$ & 2,2500 \\
\hline 4. Quartil & 291 & $24 \%$ & 79,7400 \\
\hline Total & $\mathbf{1 2 2 5}$ & $\mathbf{1 0 0} \%$ & \\
\hline
\end{tabular}

A dispersão das turfeiras pode ser vista na figura 5. Verifica-se que em áreas com altitudes baixas, correspondentes ao Segundo Planalto paranaense, existe a presença apenas de turfeiras que abrangem áreas pequenas. A ocorrência de turfeiras com grandes áreas pode ser notada somente a partir da altitude de 1000 metros, situadas no platô do Terceiro Planalto paranaense. A maior área turfosa, com 79,7400 hectares, fica localizada na porção centro sul da área de estudo.

Figura 5 - Dispersão das turfeiras em relação à altitude - área.

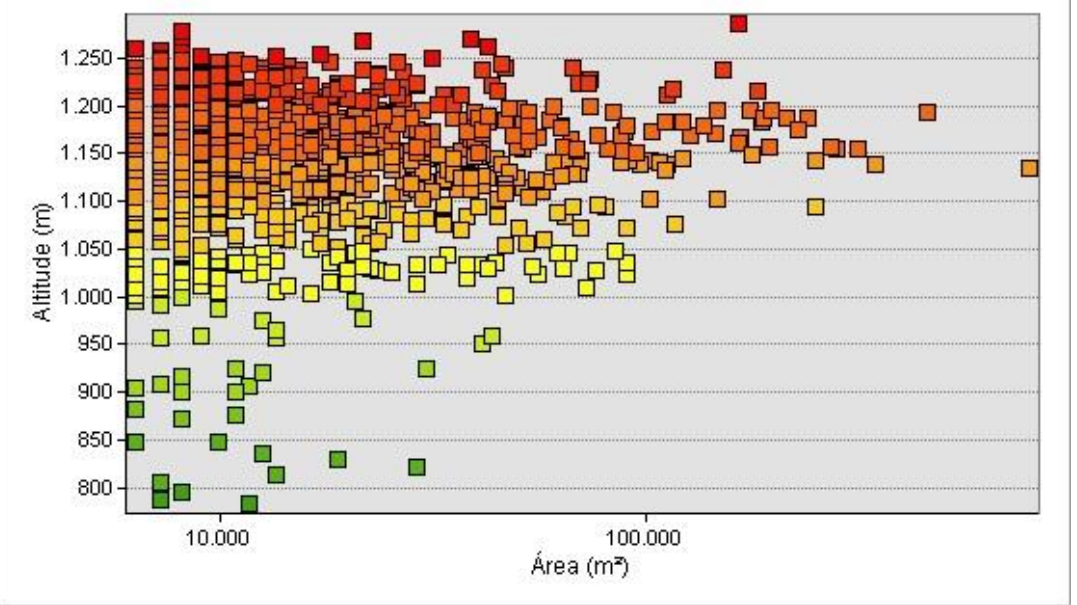

Fonte: Dados da pesquisa.

\section{Disposição das turfeiras em relação à altimetria}

Quando associadas à topografia local, as turfeiras apresentam padrão de agrupamento em áreas que apresentam maior valor de elevação. As altitudes onde as turfeiras são mais recorrentes são entre 1171 e 1185 metros, como pode ser observado na figura 6 . 
Figura 6 - Frequência de distribuição das turfeiras com relação à altitude.

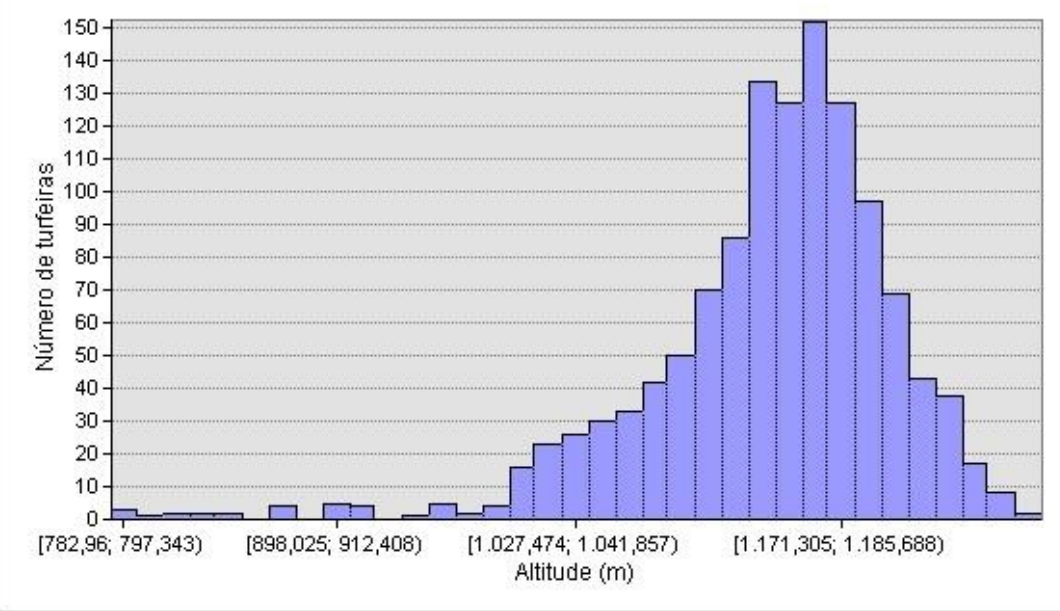

Fonte: Dados da pesquisa.

Considerando que a cota média das turfeiras seja de 1100 metros sugere-se que a maior parte das turfeiras se localiza nas altitudes mais elevadas da região, representando $79,10 \%$ do total. A figura 7 apresenta as turfeiras sobre o modelo digital do terreno, sendo possível identificar um denso agrupamento nas altitudes mais elevadas. Nesse sentido, pode-se então classificar geograficamente as turfeiras presente na área de estudo como ombrotróficas (altas), conforme o proposto por (COSTA et al. 2003).

Figura 7 - Revelo triangular área de estudo.

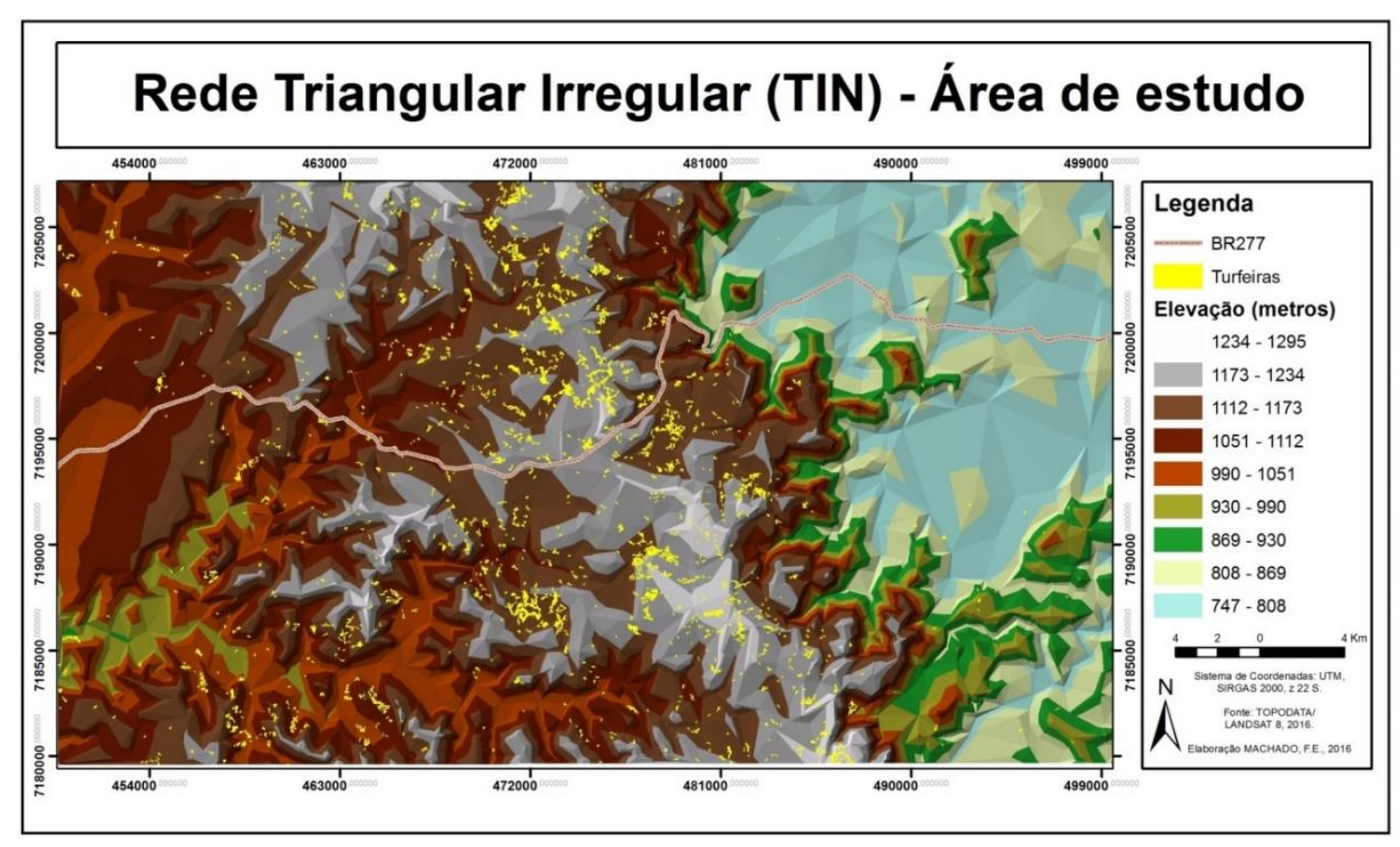

Fonte: Dados da pesquisa. 
O fator topográfico nesse caso se apresenta com um agente que contribui para a manutenção dessas áreas. Ele não pode ser considerado como fator ou agente principal, já que este é unicamente um produto das formas morfoestruturais que exercem influências na região.

Seguindo a observação disposta por Scheer e Mocochinski (2009) e Hirakawa e Kurashige (2000), sugere-se que locais com elevadas altitudes estão sujeitos, devido às condições externas que recebem, como adicional de água da chuva, temperaturas frequentemente baixas e acumulo de material orgânico, ao agrupamento, captação e fixação dos materiais essenciais para a constituição de uma turfeira. Todavia, o elemento topográfico pode influenciar na manutenção das turfas, mas não na sua origem, já que esta pode estar condicionada a um conjunto de fatores internos e externos.

\section{Correlação entre as turfeiras e lineamentos}

Com relação aos lineamentos estruturais, para Soares et al (1982), os lineamentos de expressão geomórfica são os mais frequentes na Bacia do Paraná, sendo geralmente alinhado às feições topográficas negativas, constituindo quebras uniformes no terreno e em feições nas formas do relevo continuas e vigorosamente impressas na morfologia.

O indício dos dados sobre a morfoestrutura local e evidências de campo, sugerem que a área de estudo está sob influência de lineamentos tectônicos, visíveis no modelo digital do terreno e também pelo arranjo da drenagem local, constatado por Lima (2009) que afirma que este arranjo espacial é comum em locais que apresentam o tipo de litologia presente na área de estudo.

De acordo com as observações realizadas nas análises computacionais com a relação dos itens "relevo - lineamentos - turfeiras" (figura 8) observa-se que existem duas áreas com maior representatividade, com agrupamento denso de turfeiras e presença de lineamentos importantes que podem estar condicionando-as. 
Figura 8 - Lineamentos estruturais da área de estudo.

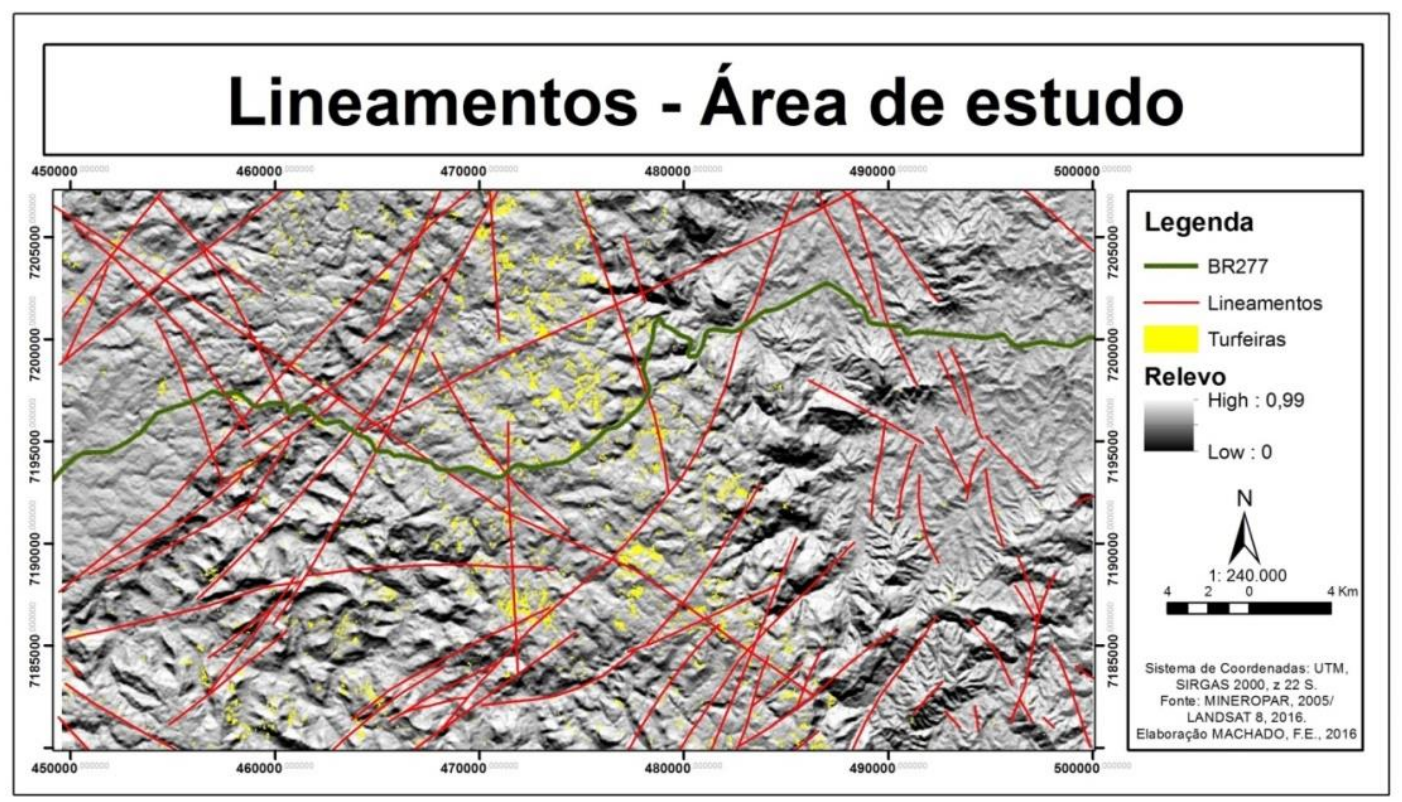

Fonte: Dados da pesquisa.

As áreas citadas, uma concentração ao sul (longitude $472777 \mathrm{E}$ e latitude 7186739S) e outra ao norte (longitude 473369 E e latitude 7197151 S) foram visitadas em campo e são aqui denominadas de bloco 1 e bloco 2 (figura 9). Ambas estão sob condicionamento de lineamentos formando blocos que em hipótese contribuíram para a instalação das turfeiras da região. As direções dos lineamentos para o bloco 1 são NNW e para o bloco 2 NNE.

Observa-se que as áreas turfosas aparentam estar "encaixadas" no relevo. Esse fato ocorre em razão de que elas normalmente estão fixadas em ambientes semiconfinados, que dificultam a saída do material que as constituem. Dessa forma, o contexto litológico da região exerce grande influência nas formas do relevo, como por exemplo, o arranjo estrutural dos corpos rochosos que pode atuar como fator dominante na instalação dos ambientes turfosos.

Ressalta-se que a concentração existente na porção central, correspondente ao bloco dois (figura 9) pode se prolongar na direção norte, excedendo os limites do recorte de estudo, sugerindo que o corredor central de zonas potencialmente turfosas pode estender-se na direção norte. Já as turfeiras que estão presentes no bloco 1 extrapolam a oeste do lineamento que em princípio influenciava no seu condicionamento.

Os dois blocos que foram visitados em campo podem ser visualizados esquematicamente na figura 9. Também pode ser visualizada nessa figura a turfeira Guará, sendo ela a única turfeira com registro de datação da região. O estudo 
realizado por Silva (2013) aponta que o material que constitui a turfeira Guará teve seu início de formação em $15.64 \mathrm{Ka}$, que compreendeu três fases paleoambientais, seguindo do Pleistoceno até a atualidade.

$\mathrm{Na}$ figura 09 é possível perceber que o relevo que compreende os blocos $1 \mathrm{e}$ 2 não variam muito, correspondendo uma topografia suavemente ondulada. No entanto em campo constatou-se que mesmo com branda ondulação existem locais onde o relevo apresenta forma côncava, facilitando a instalação das turfeiras, ambientes esses envoltos nesse caso por pequenas elevações.

Figura 9 - Esquema de concentração de turfas em dois principais

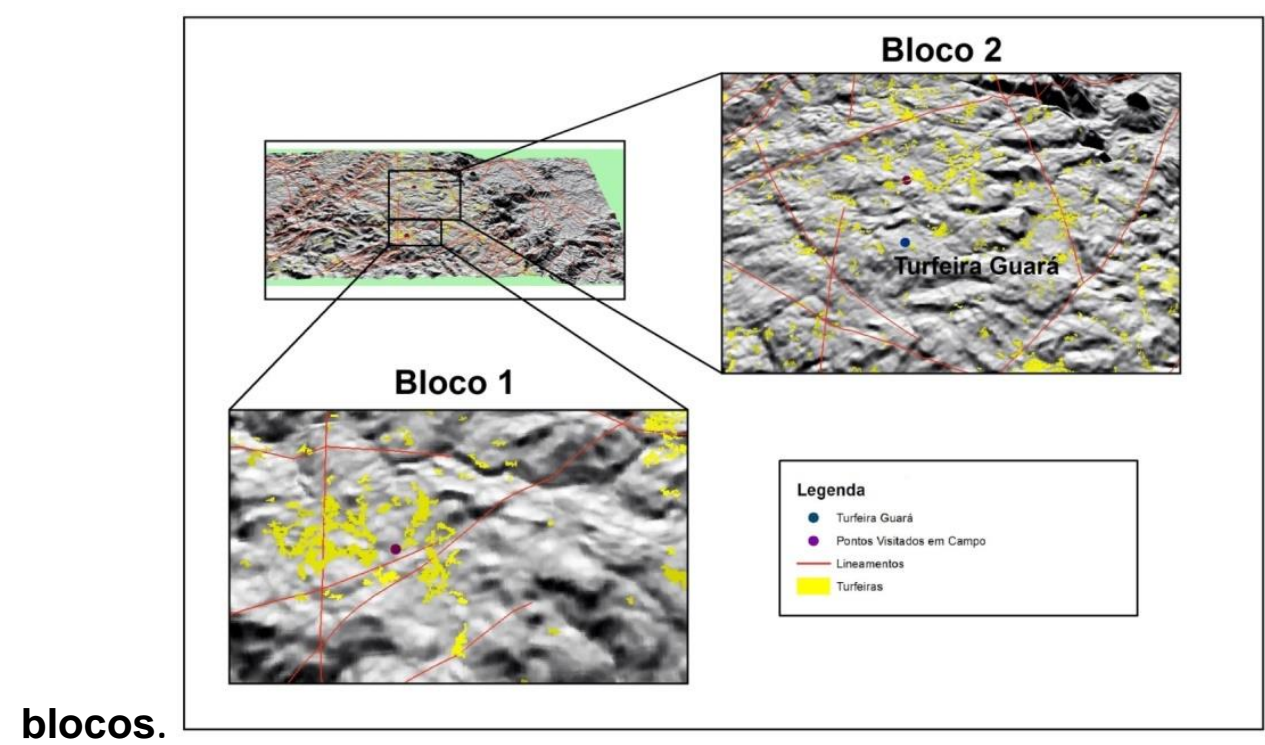

Fonte: Dados da pesquisa.

O bloco 1 visitado em campo está sobre litologia de derrames de basalto com textura afanítica e com derrames lobados, também apresentaram porções vesiculadas, mantendo manto de alteração profundo (figura 10).

Figura 10 - (A) Derrames de basalto. (B) Visão geral próximo a locais com turfeiras.

A

B
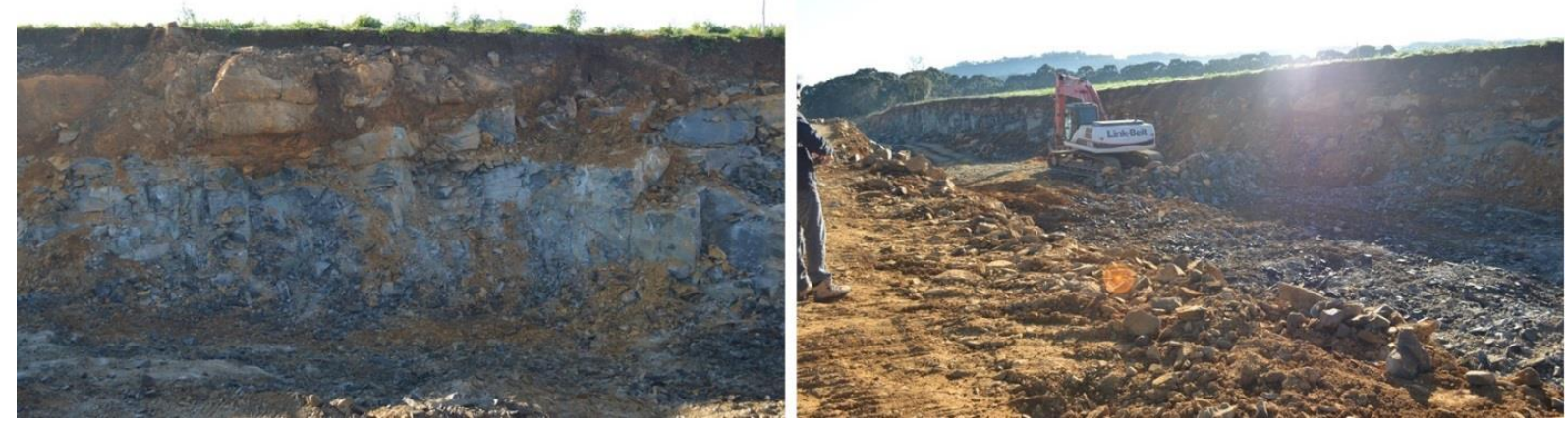

Fonte: EURICH MACHADO, F., 2016. 
A figura 11 apresenta um dos pontos com turfeira no bloco 1 visitada. Está situada sobre o material rochoso e sua espessura apresenta-se de maneira delgada. As turfeiras em geral aparentam encaixadas em porções de topo. Ainda na porção do bloco 1 constatou-se atividades antrópicas. Parte do material turfoso foi retirado dessa área para construção da rodovia PR 364, trabalho que está em andamento.

Figura 11 - (A) e (B) Zonas turfosas com interferência devido à construção da rodovia estadual PR 364 sentido Góis Artigas.

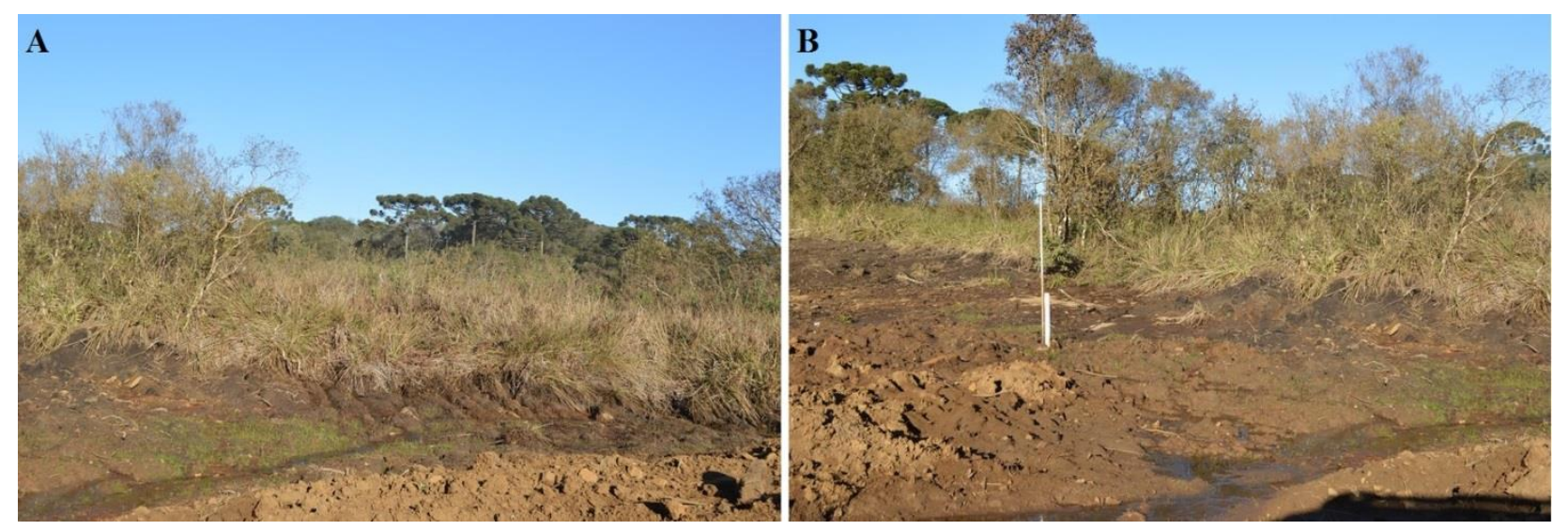

Fonte: EURICH MACHADO, F., 2016.

A área turfosa que apresentou maior tamanho em área pode ser visualizada na figura 12. A figura 12A apresenta a visão parcial da área turfosa enquanto que a figura 12B apresenta a porção sudoeste da mesma área. Em campo foi observado que, devido aos cortes realizados para a construção da rodovia e a interrupção do fluxo de água, há o avanço da vegetação de maior porte, que não são típicas de ambiente aquoso. Também constatou-se que a área turfosa normalmente acompanha o delineado do terreno, apresentando longas áreas turfosas e quase sempre interligadas umas às outras.

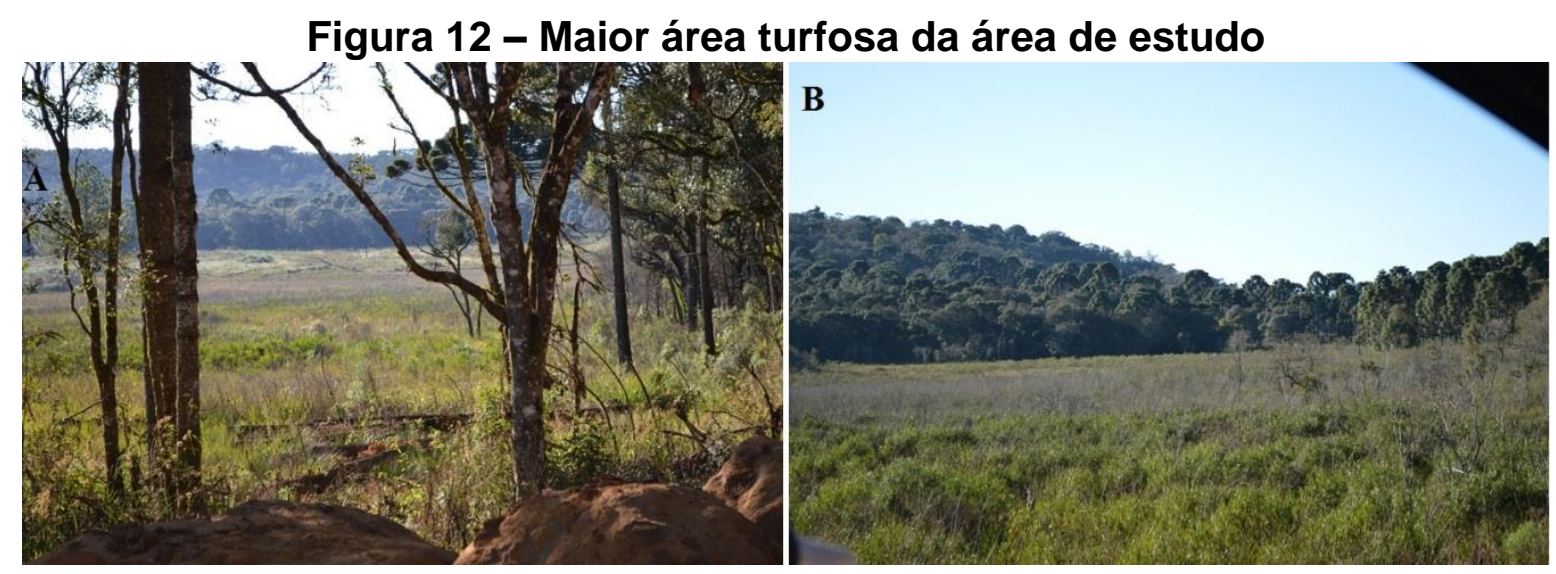

Fonte: EURICH MACHADO, F., 2016. 
Pertencente ao bloco 2 está a turfeira Guará (figura 13A), que mantêm função de alimentação de canais de drenagem que fazem parte da estrutura local. Levando em consideração o disposto por Schumm et al (2000) onde cada padrão de drenagem apresenta um significado litoestrutural, sugere-se que as áreas potencialmente turfosas do bloco 2 estão condicionadas as questões estruturais atuantes na região, já que estão estritamente relacionadas à drenagem. A figura 13B apresenta a visão geral da aglomeração visitada no bloco 2 .

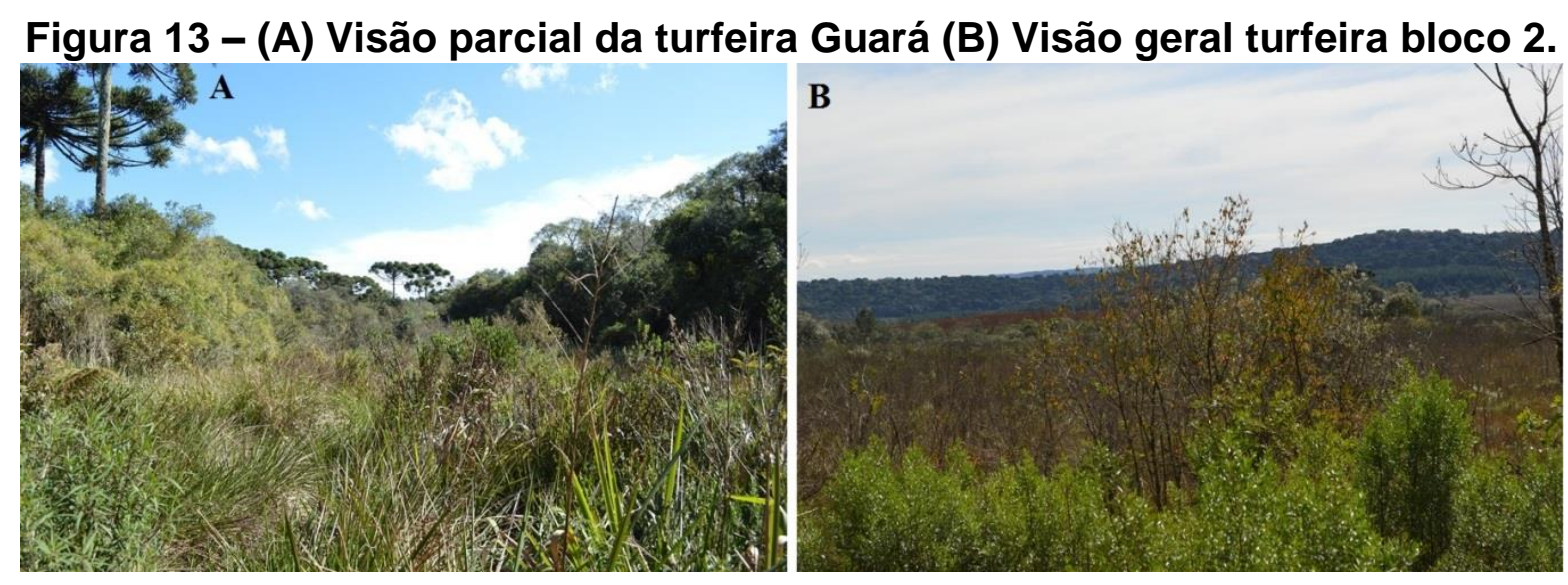

Fonte: EURICH MACHADO, F., 2016.

A morfoestrutura local tem participação importante para o delineado da região, e quando associado à textura da rocha tem-se o ambiente propício à instalação desse pedoambiente. Embora no local visitado não se tenha observado ou identificado basculamento, ainda permanece a tese que estes são o elemento determinante na formação das turfeiras. $O$ fraturamento da rocha, aparentemente é outro condicionante na instalação de nascentes e das próprias turfeiras. $\mathrm{O}$ bloco 2 , contrasta com as características das turfas do bloco 1 , as turfeiras, em sua maioria, estão ligadas a rede de drenagem no seu ponto inicial alimentando nascentes.

\section{Correlação entre as turfeiras e drenagem}

Os padrões de canais fluviais que constituem a rede de drenagem de uma bacia hidrográfica podem ser variáveis e por vezes complexo. Entretanto, quando se analisa os padrões preexistentes nota-se que a rede de drenagem está sob controle tanto das feições morfológicas locais quando as feições que foram produzidas por eventuais eventos tectônicos. Os condicionantes morfoestruturais do relevo são importantes aspectos para compreensão da evolução da rede de drenagem (COUTO et al, 2011). 
Considerando o arranjo espacial da rede de drenagem e as áreas turfosas (figura 14), observa-se que as turfeiras estão conectadas a rede de drenagem, seja na forma de nascentes ou como áreas de inundação adjacentes aos canais fluviais.

\section{Figura 14 - Rede de drenagem com aproximação dos blocos 1 e 2 visitados em campo.}

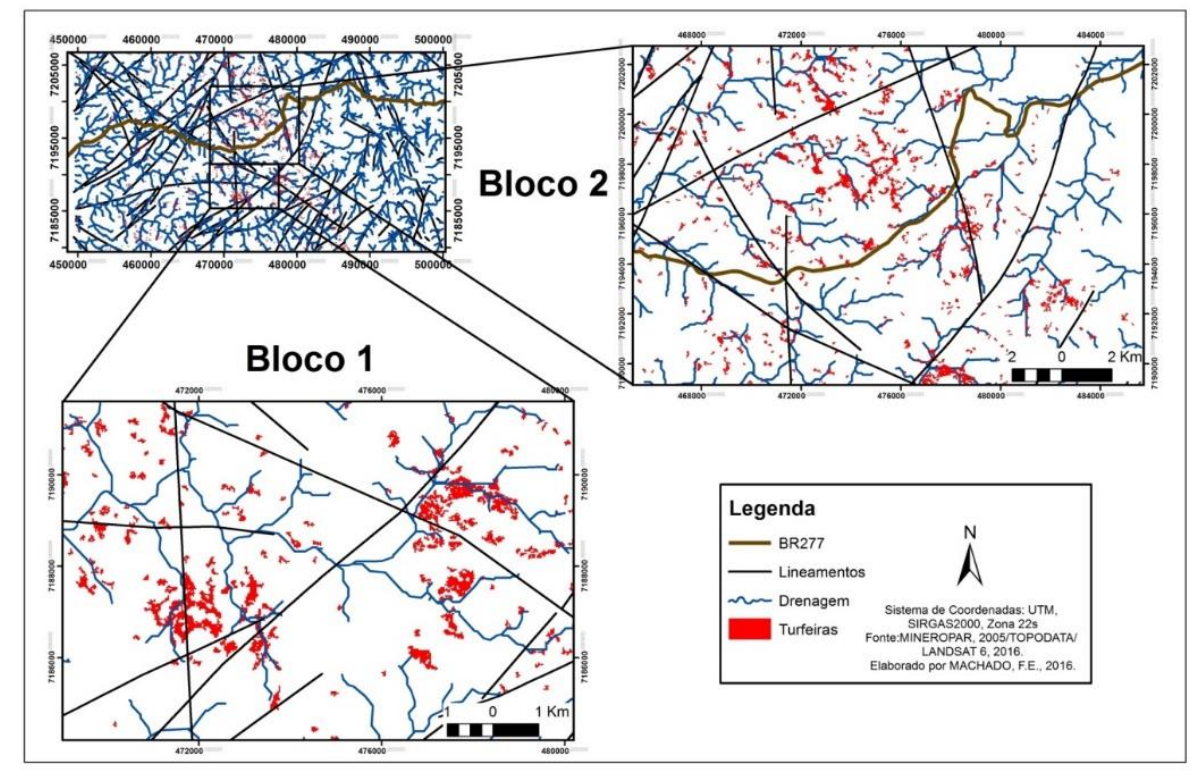

Fonte: Dados da pesquisa.

Partindo do princípio que os aspectos estruturais condicionam fortemente no arranjo espacial da rede de drenagem, pode-se sugerir que as turfeiras também recebem parte dessa influência, já que a maioria delas, nessa área, são conectadas a rede de drenagem, seja como nascente ou intermediaria a um canal.

Pode-se destacar a existência de dois cenários distintos para a área, em relação ao arranjo espacial da rede de drenagem no bloco 1, que apresenta algumas características diferentes quando comparadas com o bloco 2, todavia evidenciando o controle estrutural na configuração e ordenamento do relevo em ambos, devido as características observadas em campo. Contudo, sugere-se que as turfeiras se apresentam de formas distintas, com relação a sua conectividade ao canal, nos dois blocos quando relacionadas com a rede de drenagem.

O bloco 2 está delimitado por dois lineamentos principais, apresenta canais de baixa ordem dispostos na direção noroeste. Sugere-se que a área está sobre zonas fraturadas apresentando altos estruturais e os canais de drenagem estão ajustados as fraturas existes. O controle morfoestrutural atuante no bloco 1 são de zonas rebaixadas tectonicamente, apresentando basculamento para direção sudoeste, indicando soerguimento para o norte e rebaixamento para a direção sul. 


\section{Considerações Finais}

Verificou-se que as turfeiras que compõe a área de estudo apresentam padrão espacial de distribuição concentrada em altitudes elevadas e seguem padrão direcional de acordo com a rede de drenagem, que por sua vez estão associadas ao arcabouço litoestrutural que sustenta todo o local. Observa-se que em altitudes acima de 1000 metros há uma grande variação em tamanho das áreas turfosas, fato não repetido em áreas abaixo desta altitude.

A vegetação de altomontana que compõe a área de concentração de turfas contribui com acúmulo de matéria orgânica nos solos turfosos, visto que em altitudes elevadas as temperaturas tendem ser baixas, por conseguinte as taxas de decomposição da biomassa também são menores.

Com relação à orientação espacial das turfeiras, verificou-se que estão relacionadas ou seguem a mesma orientação da rede de drenagem. Sugerindo que o agrupamento turfoso que constitui o bloco 1 está distribuído de forma anexa ao canal de drenagem e do bloco 2 mantem-se com frequência como zonas de cabeceiras dos canais. Sugere-se que os lineamentos nas direções NNW (bloco1) e NNE (bloco2) são significativos para a configuração espacial das áreas turfosas. Visto que os agrupamentos turfosos foram identificados nas porções centrais onde eles atuam, denotando assim seu caráter controlador, o que não foi observado outras porções do terreno com mesmas características, porém sem presença de grandes lineamentos.

A hipótese de que as turfeiras apresentam esse padrão devido ao seu contexto morfoestrutural e morfoescultural confirma-se quando os elementos base para as correlações (tipo de litologia, lineamentos, altimetria e drenagem) foram associados e percebidos em campo. No entanto, os aspectos litológicos e lineamentos foram os aspectos que tiveram maior relação de influência com a distribuição e forma das turfeiras, pois os outros elementos podem ser considerados, nessa análise, como subprodutos das condições geológicas que direta ou indiretamente estabelecem influência sobre todos os outros.

Sabendo que a morfoestrutura contribui para o delineado da superfície e que áreas turfosas se instalam em locais de concavidades com drenagem precária, as condições identificadas na área de estudo são propicias para esse tipo de ambiente. Os elementos que compõe a morfoestrutura local propiciaram a formação das turfeiras e os elementos da morfoescultura mantêm as turfas até o estágio atual. A explicação para o agrupamento das áreas turfosas em apenas partes do terreno 
justifica-se pela combinação de elementos morfoestruturais e esculturais que atuam especificamente nas mesmas proporções somente nesse local.

Considerados todos os aspectos técnicos e estruturais observa-se que a combinação entre a geologia, topografia do terreno, condições climáticas, rede de drenagem e formas do relevo, influenciaram na composição e consolidação de uma área com uma grande concentração de turfeiras. Isto não ocorre da mesma maneira, por exemplo, nas áreas próximas no mesmo município ou depois da Serra da Esperança, ou seja, o fato depende de todos os aspectos ocorram de forma equilibrada.

Com relação à identificação das áreas turfosas por meio do sensoriamento remoto, os resultados foram satisfatórios, refletindo a realidade da área estudada. As imagens de satélite da série LANDSAT 8 mostraram-se eficientes quando realizado o processo de identificação do alvo estudado. Todavia, para valores exatos em relação ao tamanho de área com outros valores de escala, por exemplo, mapeamentos de detalhe são necessários.

Como sugestões para trabalhos futuros, recomenda-se a análise da composição físico-química juntamente com as condições das turfeiras dentro de uma bacia hidrográfica, quantificando quais são as influências dos ambientes turfosos à biota aquática e do estado ecológico da água. O mapeamento de detalhe, neste caso, depois de realizada a análise da composição físico-química seria um método apropriado, pois permitiria a análise dos elementos de maneira isolada.

\section{REFERÊNCIAS}

AB'SABER, A. N. Os domínios de natureza no Brasil: potencialidades paisagísticas. São Paulo: Ateliê Editorial, p. 160, 2003.

AYOADE, J. O. Introdução à climatologia para os trópicos. $5^{\underline{a}}$ ed. Rio de Janeiro: Bertrand Brasil, p. 332, 1998.

ANDRADES FILHO, C.O.; ZANI, H.; GRADELLA, F.S. Extração automática das redes de drenagem no Pantanal de Aquiduana: estudo comparativo com dados SRTM, ASTER e Carta topográfica DSG. Geografia. Rio Claro, v.34, número especial, p. 731-743, dez. 2009.

ARAÚJO, M.P. (2015). QGIS: Classificação supervisionada de imagens orbitais com o Semi-automatic classification plugin. Disponível em: <www.qgisbrasil.org > Acesso em 07 mai. 2016.

BIGARELLA, J. J. Simpósio Internacional Sobre o Quaternário. Vol. 47, Rio de Janeiro, 1975. 
BIGARELLA, J. J.; BECKER, R. D.; SANTOS, G. F. Cárstico estrutura e origem das paisagens tropicais e subtropicais: fundamentos geológicos, geográficos, alteração química e física das rochas, relevo e dômico. Florianopolis: EDUFSC, p. 425, 1994.

BÜDEL, J. Das System der Klimatischen Morphologie. Deutscher Geographentag, München, v. 27, n. 4, p.65-100, 1948.

CAMERA, G. Representação computacional de dados geográficos. In.: CASANOVA,M.; CÂMARA, G.; DAVIS, C. et al. Banco de dados geográficos. MundoGEO, Curitiba, 2005.

CAMARGO FILHO, M. Aspectos Fundamentais da Evolução Geomorfológica

Cenozóica da Bacia do rio Bananas- Guarapuava - PR. 219f. Dissertação (Mestrado em Geografia), Universidade Federal de Santa Catarina - UFSC, 1997.

CAVIGLIONE, J. H. et al. Cartas climáticas do Paraná. Londrina: IAPAR, 2000.

COSTA, C. S. B.; IRGANG, B. E.; PEIXOTO, A. R.; MARANGONI, J. C. Composição florística das formações vegetais sobre uma turfeira topotrófica da Planície Costeira do Rio Grande do Sul, Brasil. Acta Botânica. Bras. 17(2): 203-212, 2003.

COUTO, E. V.; MANIERI, D. D.; MANOSSO, F. C. et al. Correlação morfoestrutural da rede de drenagem e lineamentos da borda planáltica, Faxinal, Paraná. São Paulo, UNESP, Geociências, v. 30, n. 3, p. 315-326, 2011.

DJUWANSAH, M. Some Characteristics of Tropical Podzols in Kalimantan. Proceedings of the International Symposium on Tropical Peatlands. Hokkaido University \& Indonesian Institute of Sciences, p 33-37, 2000.

EMBRAPA- Empresa Brasileira de Pesquisa Agropecuária. Brasil em Relevo. EMBRAPA monitoramento por Satélite. 1999. Disponível em: <

http://www.relevobr.cnpm.embrapa.br/download/ > Acesso em Out. 2015.

FLORENZANO, T.G. Iniciação em Sensoriamento Remoto. São Paulo: Oficina de Textos, 2007.

FIRKOWSKI, H. Generalização cartográfica de grades retangulares regulares baseada na teoria matemática da comunicação. Tese (Doutorado em Ciências Geodésicas), Universidade Federal do Paraná, Curitiba, 2002.

GUERREIRO JUNIOR, L.A.; CAMARGO FILHO, M.; MACHADO, F.E. et al. Comparação entre áreas turfosas identificadas em carta topográfica (Guarapuava- O Ml 2838/3) e imagens do Google Earth. In.: XI- Encontro Nacional da ANPEGE. Anais... XI- ENANPEGE, Presidente Prudente - SP, Brasil, 2015.

GUERRA, A. J. T.; CUNHA, S. B. da (orgs.). Geomorfologia e Meio Ambiente. Rio de Janeiro: Bertrand Brasil, 2003.

HIRAKAWA, K.; KURASHIGE, Y. Preliminary Study on Geomorphology in the Central Kalimantan Plain with Special Reference to the Tropical Peat Formation. In.: Proceedings of the International Symposium on TROPICAL PEATLANDS. Bogor, Indonesia, p. 19-26, 2000.

ITCG - Instituto de Terras, Cartografia e Geociências. Dados e informações geoespaciais 
temáticos - Geomorfologia. Curitiba, 2008. Disponível em: < http://www.itcg.pr.gov.br> Acesso em 21 abr. 2016.

LIMA, A. G. Controle geológico e hidráulico na morfologia do perfil longitudinal em rio sobre rochas vulcânicas básicas da formação Serra Geral. 240 f. Tese (Doutorado em Geografia), Universidade Federal de Santa Catarina, Florianópolis, 2009.

MAACK, R. Geografia física do Estado do Paraná. Rio de Janeiro: Olympio, 350 p. 1968.

MACHADO, F.B.; NARDY, A.J.R.; MELO, R.P.de. et al. As rochas intrusivas da formação serra geral na porção leste da bacia do Paraná no estado de São Paulo: aspectos petrográficos e geoquímicos - resultados preliminares. Geociências. v. 24, n. 1. São Paulo: UNESP, p. 5-17, 2005.

MARCHETTI. D.A.B.; GARCIA, G.J. Princípios de fotogrametria e fotointerpretação. São Paulo: NOBEL, 1986.

MENEZES, R. Detecção remota e processamento digital de imagem - The interface of the Semi-Automatic Classification Pluguin. Gestão do Território, Universidade Nova de Lisboa, 2015.

MINEROPAR - Minerais do Panará. O Grupo Serra Geral no Estado do Paraná. v.1, v2., Curitiba, 2013. Disponível em: < http://www.mineropar.pr.gov.br/modules/conteudo/conteudo .php?conteudo=146 > acesso em 29 abr. 2016.

MINEROPAR - Minerais do Panará. Atlas geomorfológico 2006. Disponível em: <http://www.mineropar.pr.gov.br.> acesso em 29 out 2015.

MINEROPAR - Minerais do Panará. Mapas geológicos para download - Carta Litoestratigráfica/ Folha Guarapuava SG-22-VD. 2005. Disponível em: <http://www.mineropar.pr.gov.br/modules/conteudo/conteudo.php?conteudo=154> acesso em 07 jan. 2016.

MOREIRA, M. A. Fundamentos do sensoriamento remoto e metodologias de aplicação. São José dos Campos: Instituto Nacional de Pesquisas Espaciais, p. 250, 2001.

MOURA, A. C. M. Reflexões metodológicas como subsídio para estudos ambientais baseados em Análise de Multicritérios. Anais... XIV Simpósio Brasileiro de Sensoriamento Remoto, Florianópolis, Brasil, INPE, p. 2899-2906, 2007.

MÜLLER, M.L.; POTT, C.A. Cobertura pedológica na Bacia do Rio das Pedras Guarapuava - PR. In: BATTISTELLI, M. CAMARGO, M.F. HEERDT, B. Proteção e Manejo do Rio das Pedras: Relato de Experiências. Guarapuava: Editora B e D, p77-83, 2004.

NOAA - National Oceanic and Atmospheric Administration. Proxy Data. NOAA Paleoclimatology, 2008. Disponível em:

<http://www.ncdc.noaa.gov/paleo/globalwarming/proxydata.html> Acesso em 04 ago. 2016.

NOVO, E. M.L. de M. Sensoriamento remoto princípios e aplicações. $2^{\circ}$ ed. São Paulo: Edgard Blücher, 1995. 
OLIVEIRA, A.H. et al. Consistência hidrológica de modelos digitais de elevação (MDE) para definição da rede de drenagem na sub-bacia do Horto Florestal Terra Dura, Eldorado do Sul, RS. Rev. Bras. Ciência do Solo, Campinas, v. 36, p. 1259-1267, 2012.

PARRY, L.E.; CHARMAN, D.J. Modelling soil organic carbon distribution in blanket peatlands at a landscape scale. Geoderma, p. 75-84, 2013.

PENCK, W. Morphological Analysis of Land forms. London: McMillan and Co.1953.

PEREIRA, M.G.; ANJOS, L.H.C. dos; VALLADARES, G.S. Organossolos: ocorrência, gênese, classificação, alterações pelo uso agrícola e manejo. Tópicos Cio Solo, 4:233-276, 2005.

ROSS, S. L. J. Geomorfologia, Ambiente e Planejamento. 2. ed. São Paulo: Editora Contexto, 1991.

ROSTIROLLA, S. P.; ASSINE, M. L.; FERNANDES, L. A.; et al. Reativação de Paleolineamentos durante a evolução da Bacia do Paraná - o exemplo do Domo de Quatiguá. Revista Brasileira de Geociências, São Paulo, v. 30, n. 4, p.1-15, 2000.

SANTOS, J. (2013). ArcGIS 10.1: Super Análise Hidrológica com Spatial Analyst. Disponível em: <www.processaentodigital.com.br> Acesso em 21 mai. 2016.

SCHEER, M.B.; MOCOCHINSKI, A.Y. Florística vascular da Floresta Ombrófila Densa Altomontana de quatro serras no Paraná. Biota Neotropica. vol.9 no.2 Campinas Apr./June 2009.

SCHUMM, S. A.; DUMONT, J. F. ; HOLBROOK, J. M. Active tectonics and alluvial Rivers. Cambridge University Press, Cambridge, 2000.

SHIMADA, S.; TAKAHASHI, H.; KANEKO, M., et al. The Estimation of Carbon Resource in a Tropical Peatland: A Case Study in Central Kalimantan, Indonesia. In.: Proceedings of the International Symposium on tropical peatlands. Bogor, Indonesia. Hokkaido University \& Indonesian Institute of Sciences, p. 9-18, 2000.

SILVA, D.W. Caracterização paleoambiental da região de Guarapuava - PR, a partir de sedimento de turfa: um estudo de caso. 96f. Dissertação (Dissertação de Mestrado em Geografia). Universidade Estadual do Centro-Oeste - UNICENTRO, Guarapuava, 2013.

SILVA, M.L.; SILVA, A.C.; SILVA, B.P.C. surface mapping, organic matter and water stocks in peatlands of the Serra do Espinhaço Meridional - Brazil. Revista Brasileira Ciência do Solo. 37, p. 1149-1157, 2013.

SOARES, P. C.; BARCELLOS, P. E.; CSORDAS, S. M.; et al. Lineamentos em imagens de Landsat e Radar e suas implicações no conhecimento tectônico da Bacia do Paraná. In: Simpósio Brasileiro de Sensoriamento Remoto, n.2, 1982, Brasília. Anais... São José dos Campos: INPE, p.143-156, 1982.

SOUZA, S.C. (2015). Criando modelo digital de elevação de rede triangular irregular (ARCGIS). Disponível em:< http://docslide.com.br/documents/criando-modelo-digital-deelevacao-de-rede-triangular-irregular-arcgis.html> Acesso em 07 mai. 2016. 
THOMAZ, E. L.; VESTENA, L. R. Aspectos climáticos de Guarapuava-PR. Guarapuava: UNICENTRO, p. 106, 2003.

TOPODATA-Banco de Dados Geométricos do Brasil. Acesso-dados. Disponível em: $<$ http://www.dsr.inpe.br/topodata/acesso.php> Acesso em mai. 2016.

U.S. Geological Survey - USGS. (2016). Frequently Asked Questions about the Landsat Missions. Disponível em: < http://landsat.usgs.gov/band_designations_landsat_satellites .php> Acesso em mar. 2016.

WOODWARD, J. C. Quaternary Geography and the Human Past. In.: CASTREE, N.; DEMERITT, D.; LIVERMAN, D.; RHOADS, B. A. Companion to Environmental Geography. Wiley-Blackwell, Chichester, p. 198-222, 2009.

\section{NOTAS DE AUTOR}

\section{CONTRIBUIÇÃO DE AUTORIA}

Fabiula Eurich Machado - Concepção. Coleta de dados, Análise de dados, Elaboração do manuscrito, revisão e aprovação da versão final do trabalho

Maurício Camargo Filho e Marcos Aurélio Pelegrina - Coleta de dados Participação ativa da discussão dos resultados; Revisão e aprovação da versão final do trabalho.

\section{FINANCIAMENTO}

Não se aplica.

\section{CONSENTIMENTO DE USO DE IMAGEM}

Não se aplica.

APROVAÇÃO DE COMITÊ DE ÉTICA EM PESQUISA

Não se aplica.

\section{CONFLITO DE INTERESSES}

Não se aplica.

\section{LICENÇA DE USO}

Este artigo está licenciado sob a Licença Creative Commons CC-BY. Com essa licença você pode compartilhar, adaptar, criar para qualquer fim, desde que atribua a autoria da obra.

\section{HISTÓRICO}

Recebido em: 02-10-2017

Aprovado em: 03-03-2019 